\title{
Dermatofilose em bezerros da raça Nelore no Mato Grosso do Sul
}

\section{Dermatophilosis in Nelore calves in Mato Grosso do Sul}

\author{
Flávia Barbieri Bacha ${ }^{1}$; Tatiane Cargnin Faccin ${ }^{2 *}$; Stephanie Carrelo Lima ${ }^{3}$; \\ Cássia Rejane Brito Leal ${ }^{4}$; Ricardo Antônio Amaral Lemos ${ }^{4}$
}

\section{Resumo}

O objetivo deste trabalho foi descrever dois surtos de dermatofilose em bezerros da raça Nelore no Estado de Mato Grosso do Sul com características epidemiológicas peculiares à região Centro-Oeste. As taxas de morbidade e letalidade foram de $50 \%$ e $0,0025 \%$ no surto 1 e, $12,5 \%$ e $10 \%$ no surto 2 , respectivamente. Apenas bezerros da raça Nelore com idade entre 5 e 60 dias foram afetados. A maioria dos casos ocorreu em pastagens de Brachiaria brizantha durante o período chuvoso do ano. Nos dois surtos, os sinais se iniciavam com espessamento da pele, seguido por lacrimejamento e formação de crostas ao redor dos olhos e focinho. Nos casos mais graves, as lesões disseminavam-se pela face e por todo o corpo, evoluindo para acentuado espessamento generalizado da pele, com formação de dobras. As lesões de pele caracterizaram-se, histopatologicamente, por dermatite supurativa e hiperqueratose. O diagnóstico foi confirmado pela visualização de estruturas basofílicas filamentosas morfologicamente compatíveis com Dermatophilus congolensis em esfregaços corados por Gram. Os tratamentos com estreptomicina, oxitetraciclina ou penicilina associada à estreptomicina utilizados nos bezerros demonstraram ser eficientes. A doença foi confundida pelos produtores com fotossensibilização hepatógena causada por ingestão de Brachiaria spp. Este artigo discute estes resultados com vistas a auxiliar o diagnóstico correto da dermatofilose que é importante para a realização do tratamento adequado e de medidas de controle eficazes, minimizando as perdas causadas por esta doença.

Palavras-chave: Dermatophilus congolensis, dermatite, Brachiaria brizantha, bovinos

\begin{abstract}
The objective of this study was to describe two outbreaks of dermatophilosis in Nelore calves in the State of Mato Grosso do Sul with epidemiological characteristics peculiar to the Midwest. Morbidity and mortality rates were $50 \%$ and $0.0025 \%$ in the outbreak 1 , and $12.5 \%$ and $10 \%$ in the outbreak 2 , respectively. Only Nelore calves aging between 5 and 60 days were affected. Most cases occurred on pastures of Brachiaria brizantha during the rainy season. In both outbreaks, the signs started with skin thickening followed by weeping and crusting around the eyes and muzzle. In more severe cases, lesions disseminated throughout the face and the body, evolving to generalized marked thickening of the skin and wrinkling. Histology of skin lesions showed suppurative dermatitis and hyperkeratosis. The diagnosis was confirmed by viewing basophilic filamentous structures morphologically consistent with Dermatophilus congolensis in Gram stained smears. The treatment with streptomycin, oxytetracycline or penicillin associated with streptomycin used in calves demonstrated to be effective. The disease has been misdiagnosed, by the farmers, with hepatic photosensitization caused by Brachiaria spp. ingestion.
\end{abstract}

\footnotetext{
${ }^{1}$ Discente do Programa de Pós-Graduação em Ciência Animal, Faculdade de Medicina Veterinária e Zootecnia, Universidade Federal de Mato Grosso do Sul, UFMS, Campo Grande, MS. E-mail: flaviabacha@hotmail.com

${ }^{2}$ Discente do Programa de Pós-Graduação em Ciência Animal, FAMEZ/UFMS, Campo Grande, MS. E-mail: tatifaccin@hotmail.com

${ }^{3}$ Discente do Programa de Residência Profissional em Medicina Veterinária, FAMEZ/UFMS, Campo Grande, MS. E-mail: stephanie_k_lima@hotmail.com

${ }^{4}$ Profs., FAMEZ/UFMS, Campo Grande, MS. E-mail: cassia.leal@ufms.br; ricardo.lemos@ufms.br

* Autor para correspondência
} 
This article discusses these results with the aim to help in the correct diagnosis of dermatophilosis, which is important to achieve the adequate treatment and effective control measures to minimize the losses caused by this disease.

Key words: Dermatophilus congolensis, dermatitis, Brachiaria brizantha, cattle

A dermatofilose bovina é uma dermatite, causada por um actinomiceto Gram positivo, denominado Dermatophilus congolensis, que acomete uma grande variedade de animais domésticos, selvagens e também humanos (ZARIA; AMIN, 2004; GINN; MANSELL; RAKICH, 2007). A bactéria está presente na pele, que atua como barreira contra a infecção, desde que não tenha sua integridade comprometida (AMBROSE, 1996). Sua transmissão ocorre após contato com animais portadores, e a doença é mais comum em áreas tropicais e subtropicais, quentes e úmidas, após o início do período chuvoso (GINN; MANSELL; RAKICH, 2007).

Uma vez que a bactéria não é considerada de alta patogenicidade, a evolução do quadro clínico é dependente de vários fatores. Formas clínicas agudas, subagudas ou crônicas são caracterizadas pelo desenvolvimento de dermatite exsudativa superficial, seguida por formação de crostas, alopecia e espessamento da pele (ZARIA; AMIN, 2004; GINN; MANSELL; RAKICH, 2007). O estresse causado por desmama e carência alimentar ou traumatismos associados a períodos chuvosos e quentes, levam ao desequilíbrio das barreiras superficiais de defesa imunológica inespecífica. Esses fatores levam à quebra da integridade da pele, permitindo que os zoósporos de $D$. congolensis invadam o tegumento produzindo dermatite bacteriana (PEREIRA; MEIRELES, 2007). Em Mato Grosso do Sul, quando ocorre em bovinos da raça Nelore, a doença é conhecida como "mela" ou "chorona" (LEMOS; POZO; SILVEIRA, 1998; LEMOS; SILVEIRA, 2008). Esta condição geralmente está associada a bezerros mantidos em pastagem de Brachiaria brizantha, o que tem levado produtores e médicos veterinários a confundirem a doença com quadros de fotossensibilização que ocorrem em pastagens do gênero Brachiaria.
O presente trabalho tem como objetivo descrever dois surtos de dermatofilose em bezerros da raça Nelore no Estado de Mato Grosso do Sul com características epidemiológicas peculiares à região Centro-Oeste.

Dois surtos dedermatofilose foramacompanhados pelo Laboratório de Anatomia Patológica (LAP) da Faculdade de Medicina Veterinária e Zootecnia (FAMEZ) da Universidade Federal de Mato Grosso do Sul (UFMS) em 2010. O surto 1 ocorreu em outubro, no município de Camapuã e o surto 2 no município de Dois Irmãos do Buriti, em dezembro.

Durante as visitas foram colhidos dados epidemiológicos referentes ao rebanho e às características da pastagem. Os exames clínicos em bovinos doentes e coleta de material para exame laboratorial também foram realizados. As crostas foram coletadas manualmente com utilização de luvas, colocadas em saco plástico estéril, encaminhadas para o Laboratório de Bacteriologia da FAMEZ/UFMS onde foram preparados esfregaços corados pela técnica de Gram para pesquisa de $D$. congolensis. Foi realizada biopsia de pele no local das lesões em três bezerros do surto 1 e em um bezerro do surto 2. Os fragmentos de pele foram fixados em formol 10\%, processados rotineiramente para exame histológico, incluídos em parafina, cortados a $5 \mu \mathrm{m}$ de espessura e corados pela hematoxilina-eosina.

Os dados sobre a precipitação mensal acumulada (PMA) durante os surtos foram obtidos a partir do Instituto Nacional de Meteorologia (INMET), Centro de Monitoramento de Tempo, do Clima e dos Recursos Hídricos de Mato Grosso do Sul (CemtecMS), Agência de Desenvolvimento Agrário e Extensão Rural (Agraer).

O surto 1 acometeu 400 bezerros da raça Nelore, de um total de 800 , com idade entre 15 e 40 dias, 
dos quais um morreu. A maioria dos bezerros era mantida em pastagem de $B$. brizantha cv. MG5, B. brizantha cv. Marandu e uma pequena parte em $B$. decumbens. O rebanho apresentava elevada infestação de moscas Haematobia irritans. Segundo o administrador, alguns animais afetados durante este surto eram filhos de vacas, cujos bezerros também apresentaram a doença em anos anteriores. A parição iniciou-se em agosto (PMA $=1 \mathrm{~mm}$ ), os primeiros casos foram observados em setembro (PMA $=30 \mathrm{~mm})$, após o início das chuvas e a maioria dos casos ocorreu em outubro $($ PMA $=99 \mathrm{~mm})($ INMET, 2010). O tratamento foi realizado com $1000 \mathrm{mg}$ de oxitetraciclina, 500 mg de estreptomicina ou 600000 UI de penicilina associada à $630 \mathrm{mg}$ de estreptomicina em dose única, por via intramuscular, conforme a disponibilidade do medicamento na propriedade. Este tratamento foi eficaz na maioria dos casos, porém quando não havia melhora clínica, o tratamento era repetido após sete dias e acompanhado por banhos com sulfato de cobre e iodo nos bezerros com os sinais clínicos mais graves. Havia, nesta propriedade, outros 200 bovinos com um manejo diferenciado que consistia em colocar os bezerros com até 30 dias de idade em $B$. decumbens, de 30 a 60 dias em $B$. brizantha baixa e após 60 dias em $B$. brizantha bem desenvolvida. Neste manejo apenas quatro bezerros apresentaram lesões semelhantes.

A propriedade na qual ocorreu o surto 2 possuía 760 bezerros da raça Nelore e 40 mestiços Pardo Suíço. Adoeceram 100 bezerros, todos da raça Nelore com idade entre cinco e 60 dias, e destes, 10 morreram. O rebanho era divido em lotes mantidos em pastagens distintas, constituídas de B. brizantha cv. MG5, B. brizantha cv. Marandu e Panicum maximum cv. Massai, neste último, os bezerros estavam com alta infestação de carrapatos. Nesta propriedade havia bovinos em pasto de $B$. decumbens, onde não ocorreram casos da doença. Outro fato digno de nota é que, em um pasto de $B$. brizantha cv. MG5 bem desenvolvido havia um lote de 54 primíparas em que todos os bezerros adoeceram. O funcionário relatou que os casos aumentavam na época das chuvas. No ano de ocorrência do surto, o período de chuva iniciou-se no mês de setembro atingindo uma PMA de $85 \mathrm{~mm}$. Nos meses de outubro, novembro e dezembro a PMA foi de $142 \mathrm{~mm}, 186 \mathrm{~mm}$ e $132 \mathrm{~mm}$ respectivamente (INMET, 2010). O tratamento conduzido pelo proprietário consistia em $15 \mathrm{~g}$ de estreptomicina e $10 \mathrm{mg}$ de dexametasona para os casos graves e $1600 \mathrm{mg}$ de oxitetraciclina para os casos menos graves, ambos associados com o fornecimento de núcleo homeopático no sal mineral. Este tratamento também foi realizado em 2009 e a letalidade foi 40\%. Diante desses resultados insatisfatórios, o tratamento foi alterado, por recomendação de um médico veterinário, para $4000 \mathrm{mg}$ de oxitetraciclina por bezerro em dose única, por via intramuscular, obtendo-se resultados satisfatórios. Segundo relato do funcionário, a doença também ocorreu em anos anteriores e foi confundida com fotossensibilização.

Nos dois surtos, os sinais iniciavam-se com espessamento e perda da elasticidade da pele ao redor dos olhos, resultando em lacrimejamento, seguido por formação de crostas ao redor dos olhos e focinho que eram removidas facilmente. Posteriormente, houve acentuado espessamento generalizado da pele, com formação de dobras. Casos não tratados evoluíram para formação difusa de crostas pelo corpo com áreas extensas de alopecia na região ventral do abdômen e na face medial dos membros pélvicos. Nestes casos, os bezerros assumiram uma coloração amarelada ou acinzentada. Os bezerros que apresentaram alopecia evidenciaram pele despigmentada (Figura 1). Em nenhum dos surtos observou-se melhora espontânea dos sinais clínicos. Foram observadas miíases secundárias e diarreia associadas à doença no surto 2. No exame histopatológico das lesões de pele nos dois surtos foi observada dermatite supurativa e hiperqueratose. No exame bacteriológico direto foi detectada presença de formas típicas de $D$. congolensis pela demonstração de cocos Gram positivos dispostos em linhas paralelas, em forma de filamentos ramificados. 
Figura 1. Dermatofilose em bezerros da raça Nelore, sinais clínicos, surto 1. (A) Lacrimejamento e disseminação de crostas pela face. (B) Crostas ao redor de focinho e boca. (C) Crostas ao redor dos olhos. (D) Áreas de alopecia generalizadas.

A

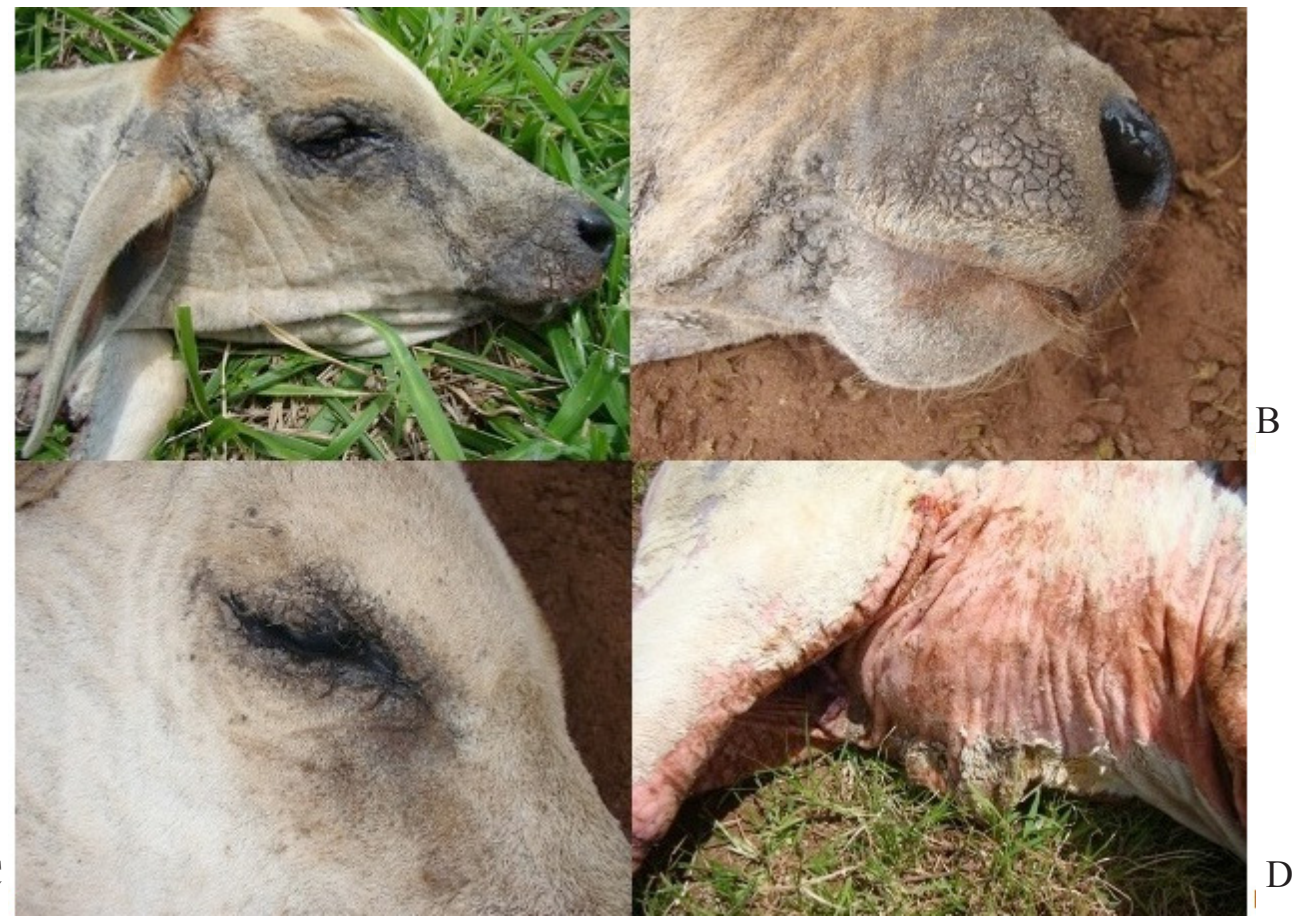

Fonte: Elaboração dos autores.

O diagnóstico da dermatofilose baseou-se no quadro clínico, no exame histopatológico de biopsias de pele e na visualização de estruturas basofílicas filamentosas morfologicamente compatíveis com D. congolensis em esfregaços corados por Gram (ZARIA; AMIN, 2004; GINN; MANSELL; RAKICH, 2007; PEREIRA; MEIRELES, 2007). Entretanto, nos casos do presente estudo foram observadas algumas particularidades relacionadas à epidemiologia e ao quadro clínico, as quais podem ser atribuídas ao fato desses surtos ocorrerem em bovinos da raça Nelore criados em condições extensivas. Não foram encontrados estudos detalhados sobre a caracterização clínica e epidemiológica da dermatofilose em zebuínos mantidos em pastagens no Brasil. Em uma descrição da doença em bovinos Nelore, feita por Cunha et al. (2010), as condições de criação eram intensivas.

A maioria dos casos ocorreu em pastagens de B. brizantha durante o período chuvoso do ano que se iniciou em setembro com precipitação mensal acumulada de $30 \mathrm{~mm}$ no surto 1 e $85 \mathrm{~mm}$ no surto 2 (INMET, 2010). Isso pode ser explicado pelas características morfológicas da planta que provocam micro lesões na pele favorecendo a penetração do agente. $\mathrm{O}$ trauma de pele e a umidade prolongada são os dois fatores mais importantes envolvidos na patogênese da doença. Os zoósporos são incapazes de superar as barreiras de proteção do pelo, da película lipídica superficial e do estrato córneo e, sua entrada é facilitada pela quebra na superfície da pele. Traumas por ectoparasitas e vegetações grosseiras podem atuar como portas de entradas para o micro-organismo. Os carrapatos e moscas também podem atuar como vetores mecânicos. Além do trauma de pele, a umidade prolongada é necessária para ativação, proliferação e disseminação dos zoósporos e também pode agir na barreira da pele através da dissolução da película lipídica superficial e do amolecimento do estrato córneo (GINN; MANSELL; RAKICH, 2007). 
A ocorrência de casos em pastos de $P$. maximum no surto 2 pode ter sido em decorrência da alta infestação de carrapatos. Em Mato Grosso do Sul, surtos com casos graves caracterizados por lesões generalizadas e mortes por septicemia foram diagnosticados em bovinos das raças Brangus e Braford associados a elevadas infestações por carrapatos (LEMOS; SILVEIRA, 2008). Infestações elevadas por Rhipicephalus (Boophilus) microplus são associadas à ocorrência de lesões generalizadas de dermatofilose e, como essas lesões não ocorrem somente nos locais de predileção do carrapato, acredita-se que a importância da infestação parasitária está relacionada à imunossupressão do hospedeiro mais do que a transmissão biológica ou mecânica (GINN; MANSELL; RAKICH, 2007; LEMOS; SILVEIRA, 2008). As lesões de pele ocorrem devido à hipersensibilidade retardada como resultado da alimentação repetida dos carrapatos, fornecendo uma porta de entrada para D. Congolensis, aos efeitos sistêmicos dos fatores imunomoduladores, como a prostaglandina E2 (PGE2) presente na saliva de carrapatos, não sendo assim fatores predisponentes à doença (ZARIA; AMIN, 2004).

Nesse estudo os percentuais de morbidade e letalidade foram de $50 \%$ e $0,0025 \%$ no surto 1 e, $12,5 \%$ e $10 \%$ no surto 2 , respectivamente. Nos casos em que o tratamento empregado foi realizado com fármacos administrados na posologia correta, a letalidade foi baixa. Por outro lado, a não realização do tratamento ou a utilização de subdoses resultou em coeficientes de letalidade de 10\%. Existem poucos relatos sobre os coeficientes de morbidade e letalidade da doença no Brasil. Em outro surto relatado no Mato Grosso do Sul, em bezerros da raça Nelore, a morbidade foi de 18,63\% (LEMOS; FERREIRA; POZO, 1996). Estudos realizados em países africanos mencionam taxas de prevalência de até $50 \%$ durante as estações chuvosas (ZARIA; AMIN, 2004).

No presente estudo foram afetados apenas bezerros com idade entre 5 e 60 dias. Em outro relato da doença em Mato Grosso do Sul, a idade variou de 60 a 90 dias (LEMOS; FERREIRA; POZO, 1996). Outros autores revelam que bovinos de todas as idades são susceptíveis, incluindo bezerros com poucas semanas de vida (ZARIA; AMIN, 2004; PEREIRA; MEIRELES, 2007; RADOSTITS et al., 2007). Não foi possível determinar por que nestes surtos apenas os bezerros foram acometidos. A infecção congênita tem sido reportada em cordeiros e bezerros (GINN; MANSELL; RAKICH, 2007) e as respostas imunes na pele e as respostas de anticorpos sistêmicos a antígenos bacterianos em ovinos são adquiridas através de infecções naturais e contribuem para a resistência (NORRIS; COLDITZ; DIXON, 2008).

No surto 2, onde havia bezerros mestiços Pardo Suíço, criados nas mesmas condições que os da raça Nelore, ocorreram casos apenas nos zebuínos. Embora isso possa ser atribuído a diferenças anatômicas da pele destes bovinos, deve-se considerar que a doença também afeta bovinos de raças taurinas sendo estas consideradas mais susceptíveis (HYSLOP, 1980). Algumas raças africanas são citadas como resistentes e os zebuínos e raças europeias como susceptíveis à dermatofilose (ZARIA, 1993). Fatores genéticos são menos entendidos, mas devem estar envolvidos, pois algumas raças de bovinos parecem ser mais resistentes à doença que outras. Estudo realizado por Maillard et al. (2002) revelou em uma população de bovinos a existência de predisposição genética à infecção por $D$. congolensis correlacionada com a presença de um haplótipo BoLA de classe II, uma proteína do complexo de histocompatibilidade principal.

Os bezerros afetados tinham a pele despigmentada, o que é um caractere indesejável para raça Nelore. A coloração da pele parece influenciar na ocorrência da doença, porque algumas raças com a pele clara podem ser mais susceptíveis à infecção. O efeito da despigmentação também pode ser observado em bovinos com áreas localizadas de pele clara, nas quais as lesões são mais severas 
quando comparadas a áreas pigmentadas (GINN; MANSELL; RAKICH, 2007).

Os sinais clínicos foram semelhantes nos dois surtos, com as lesões se iniciando ao redor dos focinhos eolhos e quandonão tratadas disseminavamse para todo o corpo. Essa distribuição das lesões é que ocorre com maior frequência em bezerros (ZARIA; AMIN, 2004). Esses autores relatam que a distribuição das lesões é variável e está associada à causa ou às causas predisponentes. Nos bovinos jovens, a infecção se inicia ao redor do focinho provavelmente a partir do contato com o úbere infectado da mãe e as lesões podem se estender pela cabeça e pescoço (RADOSTITS et al., 2007). Nos bezerros mantidos em pastagem de $B$. brizantha, sugere-se que as micro lesões causadas por essa forrageira nas faces dos bezerros foram a porta de entrada da infecção. Entretanto, nos casos ocorridos em pastagens de P. maximum em que o carrapato foi considerado o fator predisponente, as lesões apresentaram a mesma distribuição.

Nos dois surtos as lesões histopatológicas foram semelhantes às descritas por outros autores (LEMOS; POZO; SILVEIRA, 1998; GINN; MANSELL; RAKICH, 2007; LEMOS; SILVEIRA, 2008).

$\mathrm{Na}$ propriedade em que ocorreu o surto 2, a doença ocorria em anos anteriores, no entanto era diagnosticada como fotossensibilização causada pela ingestão de $B$. brizantha, evidenciando a importância do diagnóstico diferencial. O diagnóstico diferencial com a fotossensibilização hepatógena é importante nos casos da forma da doença com lesões generalizadas, que ocorre predominantemente em bezerros da raça Nelore. Embora as lesões de pele das duas apresentem semelhanças, a retração cicatricial na extremidade das orelhas, observada na fotossensibilização, não ocorre na dermatofilose e não foi observada em nenhum dos casos destes surtos.

Outros diagnósticos diferenciais são com a dermatomicose e a papilomatose. Um aspecto prático importante no diagnóstico diferencial é que as crostas na dermatofilose destacam-se facilmente, enquanto na dermatomicose as crostas são circunscritas, bem delimitadas (às vezes, coalescentes), pouco elevadas, secas e não são removidas com facilidade. Quanto à papilomatose, em sua forma nodular, o aspecto das lesões é diferente, pois geralmente os papilomas são massas nodulares pedunculadas, difíceis de serem removidas e sangram quando são extraídas. A papilomatose plana caracteriza-se por ser circular, discreta, baixa, geralmente múltiplas, sempre sésseis e com até $2 \mathrm{~cm}$ de diâmetro (RADOSTITS et al., 2007). Além das diferenças nos aspectos clínicos, a papilomatose não responde ao tratamento com antibióticos e apresenta, histologicamente, lesões que podem ser diferenciadas com facilidade. Outro diagnóstico diferencial é com casos de infecção pelo vírus da diarreia viral bovina associado à dermatite generalizada. Nesta forma da doença, além das alterações de pele, ocorrem lesões ulcerativas no trato digestivo que não são observadas na dermatofilose (FERREIRA et al., 2008; LEMOS; SILVEIRA, 2008).

Os tratamentos com estreptomicina, oxitetraciclina ou estreptomicina associada à penicilina demonstraram ser eficientes. Em termos de taxa de recuperação, ganho de peso, evitar recidivas e prevenção da morte, a gentamicina é o tratamento mais eficaz, seguido por uma combinação de penicilina e estreptomicina e, finalmente, de oxitetraciclina de longa ação (HAMID; MUSA, 2009). O tratamento com oxitetraciclina foi eficaz em casos de dermatofilose generalizada em bezerros Braford que não respondem ao tratamento com estreptomicina (LEMOS; SILVEIRA, 2008). A terapia parenteral tem demonstrado ser mais eficiente do que o tratamento tópico (ZARIA; AMIN, 2004).

No Brasil, especialmente em Mato Grosso do Sul, não existem estudos detalhados sobre a ocorrência da doença. A dermatofilose é classificada na África como uma das quatro principais doenças 
bacterianas que atingem bovinos, devido a grandes perdas econômicas como diminuição da produção de carne e de leite, baixa classificação do couro e, até mesmo, a morte dos animais, tendo uma importância equivalente à pleuropneumonia contagiosa bovina e à brucelose (ZARIA, 1993). Outras perdas relacionadas a esta doença incluem infertilidade, abate precoce dos animais afetados, predisposição a infecções secundárias e miíases, e quando as lesões atingem o úbere ou tetos, a amamentação dos bezerros pode ser dificultada, resultando em baixa taxa de crescimento (GINN; MANSELL; RAKICH, 2007). Outro aspecto a ser ressaltado é que a doença é confundida com fotossensibilização hepatógena causada por ingestão de Brachiaria spp. Assim, o reconhecimento da doença com a realização de um diagnóstico preciso é importante para a realização do tratamento correto e de medidas de controle eficazes, minimizando as perdas causadas pela dermatofilose.

Os dados obtidos do presente estudo demonstram que a dermatofilose é uma causa potencial de perdas econômicas em bezerros Nelore no Mato Grosso do Sul. Os surtos estão relacionados a condições que causam micro lesões na pele. Dentre os fatores predisponentes destacam-se a ocorrência de chuvas intensas, pastagens grosseiras como B. brizantha e infestações elevadas por ectoparasitas.

\section{Agradecimentos}

Conselho Nacional de Desenvolvimento Científico e Tecnológico (CNPq n ${ }^{\circ}$ 14/2011 Projeto Universal Proc.483211/2012-5) pelo apoio financeiro.

\section{Referências}

AMBROSE, N. C. The pathogenesis of dermatophilosis. Tropical Animal Health and Production, Edinburgh, v. 28, n. 2, p. 29S-37S, 1996.

CUNHA, P. H. J.; SIQUEIRA, A. K.; OLIVEIRA FILHO, J. P.; BADIAL, P. R.; OLIVEIRA, A. P.; LISTONI, F. J. P.; RIBEIRO, M. G.; BORGES, A. S. Dermatofilose em bovinos criados em regime de confinamento. Veterinária e Zootecnia, Botucatu, v. 17, n. 2, p. 224-228, 2010.

FERREIRA, L. C. L.; FLORES, E. F.; DRIEMEIER, D.; MELO, O.; LEMOS, R. A. A. Doença das mucosas associada à dermatite generalizada em bovinos, Mato Grosso do Sul. Pesquisa Veterinária Brasileira, Seropédica, v. 28, n. 6, p. 285-292, 2008.

GINN, P. E.; MANSELL, J. E. K. L.; RAKICH, P. M. Skin and appendages: dermatophilosis. In: MAXIE, M. G. (Ed.). Jubb, kennedy and palmer's pathology of domestic animals. 5. ed. Philadelphia: Elsevier, 2007. v. 1, p. 680-684.

HAMID, M. E.; MUSA, M. S. The treatment of bovine dermatophilosis and its effect on some haematological and blood chemical parameters. Revue Scientifique et Technique/Office International des Epizooties, Paris, v. 28, n. 3, p. 1111-1118, 2009.

HYSLOP, N. St. G. Dermatophilosis (streptothricosis) in animals and man. Comparative Immunology, Microbiology and Infectious Diseases, Oxford, v. 2, n. 4, p. 389-404, 1980.

INSTITUTO NACIONAL DE METEOROLOGIA - INMET. Ministério da Agricultura Pecuária e Abastecimento. Agraer. Campo Grande: Estado de Mato Grosso do Sul, 2010. Disponível em: <www.agraer. ms.gov.br/cemtec >. Acesso em: 27 jan. 2014.

LEMOS, R. A. A.; FERREIRA, L. C. L.; POZO, C. F. Dermatofilose em bezerros lactentes. In: ENCONTRO DE LABORATÓRIOS DE DIAGNÓSTICO VETERINÁRIO DO CONE SUL, 1996, 1., Campo Grande. Anais... Campo Grande: UFMS, 1996. p. 48-49.

LEMOS, R. A. A.; POZO, C. F.; SILVEIRA, A. C. Enfermidades do sistema tegumentar: dermatofilose. In: LEMOS, R. A. A. Principais enfermidades de bovinos de corte do mato grosso do sul: reconhecimento e diagnóstico. Campo Grande: Universidade Federal de Mato Grosso do Sul, 1998. p. 487-491.

LEMOS, R. A. A.; SILVEIRA, A. C. Doenças que afetam o sistema tegumentar: dermatofilose. In: LEMOS, R. A. A; LEAL, C. R. B. Doenças de impacto econômico em bovinos de corte: perguntas e respostas. Campo Grande: Editora UFMS, 2008. p. 349-354.

MAILLARD, J. C.; CHANTAL, I.; BERTHIER, D.; THEVENON, S.; SIDIBE, I.; RAZAFINDAIBRE, H. Molecular immunogenetics in susceptibility to bovine dermatophilosis. Annals New York Academy of Sciences, New York, v. 969, n. 10, p. 92-96, 2002.

NORRIS, B. J.; COLDITZ, I. G.; DIXON, T. J. Fleece rot and dermatophilosis in sheep. Veterinary Microbiology, Amsterdam, v. 128, n. 3-4, p. 217-230, 2008. 
PEREIRA, D. B.; MEIRELES, M. C. A. Dermatofilose. In: RIET-CORREA, F.; SCHILD, A. L.; LEMOS, R. A. A.; BORGES, J. R. J. Doenças de ruminantes e eqüideos. 3. ed. Santa Maria: Pallotti, 2007. v. 1, p. 280-286.

RADOSTITS, O. M.; GAY, C. C.; HINCHCLIFF, K. W.; CONSTABLE, P. D. Dermatophilosis (mycotic dermatitis, cutaneous streptotrichosis, senkobo disease of cattle, lumpy wool of sheep). In: . Veterinary medicine: a textbook of the diseases of cattle, horses, sheep, pigs, and goats. 10. ed. Philadelphia: Elsevier, 2007. p. 1048-1051.
ZARIA, L. T. Dermatophilus congolensis infection (dermatophilosis) in animals and man! An update. Comparative Immunology, Microbiology and Infectious Diseases, Oxford, v. 16, p. 179-222, 1993.

ZARIA, L. T.; AMIN, J. D. Bacterial diseases: dermatophilosis. In: COETZER, J. A. W.; TUSTIN, R. C. Infectious diseases of livestock. 2. ed. Southern Africa: Oxford, 2004. v. 3, p. 2026-2041. 